\title{
Stacked Microsurgical Autologous Flap Breast Reconstruction Is an Ideal Option after Unilateral Nipple-Sparing Mastectomy
}

\author{
Jordan D. Frey, MD ${ }^{1} \quad$ Michael Alperovich, MD ${ }^{1} \quad$ Christina Y. Ahn, MD ${ }^{1}$ Robert J. Allen, MD ${ }^{1}$ \\ ${ }^{1}$ Hansjörg Wyss Department of Plastic Surgery, NYU Langone Medical \\ Center, New York, New York \\ Address for correspondence Robert J. Allen, MD, Hansjörg Wyss \\ Department of Plastic Surgery, NYU Langone Medical Center, 630 3rd \\ Avenue, Suite 601, New York, NY 10017 \\ J Reconstr Microsurg Open 2016;1:92-95. \\ (e-mail: robert.allen@nyumc.org).
}

\begin{abstract}
Background Nipple-sparing mastectomy (NSM) allows for complete preservation of the nipple-areola complex and is increasing in popularity. Autologous options in NSM provide an aesthetic reconstruction in a single stage; however, donor tissue may be scarce in these patients. Stacked microsurgical breast reconstruction, especially in unilateral cases, is an attractive alternative in NSM that is yet to be described.

Methods Patients undergoing NSM with stacked autologous flap reconstruction were identified with demographics, intraoperative variables, and outcomes analyzed.

Results Six patients who underwent unilateral NSM with stacked autologous free flaps were identified. The average patient age was 50.17 years and body mass index was 21.67. Average follow-up was 28.62 months. Five (83.3\%) patients underwent unilateral NSM and reconstruction for a therapeutic indication. The average mastectomy weight was 235.67 grams. All patients were reconstructed with stacked deep inferior epigastric perforator flaps. The average total flap weight was 397.33 grams. Anastomoses in five stacked flaps (83.3\%) were performed in an anterograde/retrograde fashion to the internal mammary (IMA) vessels. In one (16.7\%) stacked flap, the two flaps were anastomosed in series to the IMA. There were no major complications and three

Keywords

- nipple-sparing mastectomy

- autologous reconstruction

- breast cancer incidences of minor complications. There were no incidences of partial or complete flap loss. The average number of secondary procedures was 0.83 per patient.

Conclusion Stacked microsurgical autologous breast flaps provide an optimal reconstruction after NSM and may be considered the reconstruction of choice in patients undergoing unilateral NSM with inadequate donor site tissue for single-flap reconstruction.
\end{abstract}

Nipple-sparing mastectomy (NSM) is the latest advancement in the treatment of breast cancer, which permits complete preservation of the nipple-areola complex (NAC). Recent studies suggest similar recurrence rates with NSM compared with traditional mastectomy techniques. ${ }^{1-6}$ Moreover, NSM has been demonstrated in multiple studies to be a safe and effective procedure from a reconstructive perspective, with acceptably low rates of NAC necrosis among other complica-

received

May 25, 2016

accepted

June 7, 2016

published online

September 2, 2016 $10.1055 / \mathrm{s}-0036-1588030$ ISSN 2377-0813. tions. ${ }^{7-12}$ As the indications for NSM continue to be established, the popularity of this procedure has risen among both patients and surgeons.

NSM allows for the complete range of reconstructive procedures, including both prosthetic and autologous options. $^{13-15}$ For many patients, NSM with microsurgical autologous reconstruction is an attractive option as it provides for a natural-appearing breast in a single procedure.

Copyright $@ 2016$ by Thieme Medical Publishers, Inc., 333 Seventh Avenue, New York, NY 10001, USA.

License terms

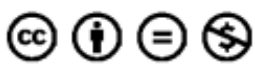


Important considerations in microsurgical breast reconstruction in NSM have been delineated previously. ${ }^{14,15}$ of the important decisions in microsurgical NSM reconstructions, the most crucial decision is of flap selection. ${ }^{15}$

Patients undergoing NSM tend to have low body mass indices (BMIs), ${ }^{15}$ thus complicating flap selection given a potential paucity of donor site tissue. In certain patients with inadequate donor site options, stacked microsurgical flaps are an excellent alternative after NSM. This option is particularly attractive in patients undergoing unilateral NSM in whom no single flap would adequately match the natural, ptotic appearance of the contralateral native breast. While described for reconstruction after total skin-sparing mastectomy, stacked flaps have not been specifically described after NSM. ${ }^{16-20}$ We therefore aim to describe our experience and outcomes with stacked microsurgical autologous breast reconstruction after NSM.

\section{Methods}

All patients undergoing NSM at the New York University Langone Medical Center from 2006 to June 2015 were identified. Patients undergoing unilateral NSM with stacked autologous free flaps were then isolated. Patient demographics, operative details, neoadjuvant therapy, indications for mastectomy, and oncologic and reconstructive outcomes, including flap failure, mastectomy flap necrosis, NAC necrosis, and infection among other variables, were collected and analyzed. Descriptive statistics and measures of central tendency were used to describe absolute and mean results, respectively.

\section{Results}

A total of six patients who underwent unilateral NSM with stacked microsurgical autologous free flaps were identified. (-Table 1) The average patient age was 50.17 years and average patient BMI was $21.67 \mathrm{~kg} / \mathrm{m}^{2}$. Average follow-up was 28.62 months. No patient had a smoking history or a history of diabetes mellitus or other comorbidities that would impair wound healing. Two (33.3\%) patients had prior radiation therapy. Five (83.3\%) patients underwent unilateral NSM and reconstruction for a therapeutic indication. One (16.7\%) patient underwent unilateral NSM and reconstruction for a BRCA1 mutation after she had previously undergone a therapeutic mastectomy and superior gluteal artery perforator (SGAP) flap reconstruction for the contralateral breast. Four (66.7\%) patients had NSM performed through a vertical radial incision, while two (33.3\%) had NSM performed through a lateral radial incision. The average mastectomy weight was 235.67 grams. The most common histologic tumor type was ductal carcinoma in situ (four patients) followed by invasive ductal carcinoma (two patients) and invasive lobular carcinoma (one patient). One (16.7\%) patient had a positive sentinel lymph node biopsy. The most common cancer stage was stage 0 (four patients) followed by stage IA (one patient) and stage $2 \mathrm{~B}$ (one patient). One (16.7\%) patient underwent postoperative chemotherapy while no patient underwent postoperative radiation therapy.
Table 1 Patient demographics, intraoperative variables, and secondary procedures performed

\begin{tabular}{|c|c|}
\hline Patient age $(\mathrm{y})$ & 50.17 \\
\hline BMI $\left(\mathrm{kg} / \mathrm{m}^{2}\right)$ & 21.67 \\
\hline Follow-up (mo) & 28.62 \\
\hline Smoking history & $0(0.0 \%)$ \\
\hline Diabetes mellitus & $0(0.0 \%)$ \\
\hline Prior radiation therapy & $2(33.3 \%)$ \\
\hline \multirow{2}{*}{$\begin{array}{l}\text { Indication for } \\
\text { mastectomy }\end{array}$} & Therapeutic: 5 (83.3\%) \\
\hline & Prophylactic: 1 (16.7\%) \\
\hline \multirow[t]{2}{*}{ Mastectomy incision } & Vertical: 4 (66.7\%) \\
\hline & Lateral: 2 (33.3\%) \\
\hline Mastectomy weight $(\mathrm{g})$ & 235.67 \\
\hline \multirow[t]{3}{*}{ Pathologic stage } & Stage 0: 4 (66.7\%) \\
\hline & Stage IA: $1(16.7 \%)$ \\
\hline & Stage 2B: 1 (16.7\%) \\
\hline $\begin{array}{l}\text { Postoperative } \\
\text { chemotherapy }\end{array}$ & $1(16.7 \%)$ \\
\hline Postoperative radiation & $0(0.0 \%)$ \\
\hline Flap choice & DIEP: $6(100.0 \%)$ \\
\hline Flap weight $(\mathrm{g})$ & 397.33 \\
\hline \multirow[t]{2}{*}{$\begin{array}{l}\text { Anastomotic } \\
\text { technique }\end{array}$} & $\begin{array}{l}\text { Anterograde/retrograde } \\
\text { IMA: } 5(83.3 \%)\end{array}$ \\
\hline & Serial IMA: 1 (16.7\%) \\
\hline \multirow{2}{*}{$\begin{array}{l}\text { Flap monitoring } \\
\text { method }\end{array}$} & Skin paddle: 6 (100.0\%) \\
\hline & Implantable Doppler: 1 (16.7\%) \\
\hline $\begin{array}{l}\text { Average number of } \\
\text { secondary procedures }\end{array}$ & 0.83 \\
\hline \multirow{4}{*}{$\begin{array}{l}\text { Secondary } \\
\text { procedures performed }\end{array}$} & Fat grafting: 5 (83.3\%) \\
\hline & Skin paddle excision: 3 (50.0\%) \\
\hline & Breast mound revision: 2 (33.3\%) \\
\hline & Mastopexy: 1 (16.7\%) \\
\hline
\end{tabular}

Abbreviations: BMI, body mass index; DIEP, deep inferior epigastric perforator; IMA, internal mammary artery.

All patients were reconstructed with stacked deep inferior epigastric perforator (DIEP) flaps. The average total flap weight was 397.33 grams. All flaps were monitored with a skin paddle, while one flap also used an implantable Doppler device. Anastomoses in five (83.3\%) stacked flaps were performed in an anterograde/retrograde fashion to the internal mammary (IMA) vessels. In one (16.7\%) stacked flap, the two flaps were anastomosed in series to the IMA. Three (50\%) flaps were neurotized.

There were no major complications and three incidences of minor complications (-Table 2). Minor complications included one $(16.7 \%)$ instance of minor mastectomy flap necrosis managed with local wound care only and two (33.3\%) instances of fat necrosis, one of which was excised in the operating room and one of which was treated with 
Table 2 Complications in patients undergoing stacked microsurgical autologous breast reconstruction after nipple-sparing mastectomy

\begin{tabular}{|c|c|}
\hline \multirow{7}{*}{$\begin{array}{l}\text { Major } \\
\text { complications }\end{array}$} & Complete flap loss: 0 (0.0\%) \\
\hline & Partial flap loss: 0 (0.0\%) \\
\hline & Anastomotic revision: $0(0.0 \%)$ \\
\hline & Full-thickness nipple necrosis: 0 (0.0\%) \\
\hline & Major mastectomy flap necrosis: $0(0.0 \%)$ \\
\hline & Cellulitis (intravenous antibiotics): $0(0.0 \%)$ \\
\hline & Hematoma: $0(0.0 \%)$ \\
\hline \multirow{5}{*}{$\begin{array}{l}\text { Minor } \\
\text { complications }\end{array}$} & Minor mastectomy flap necrosis: 1 (16.7\%) \\
\hline & Fat necrosis: 2 (33.3\%) \\
\hline & Partial-thickness nipple necrosis: $0(0.0 \%)$ \\
\hline & Cellulitis (oral antibiotics): 0 (0.0\%) \\
\hline & Seroma: $0(0.0 \%)$ \\
\hline
\end{tabular}

liposuction. There were no incidences of partial or complete flap loss. The average number of secondary procedures performed was 0.83 per patient. The most common secondary procedures performed were fat grafting (five patients), skin paddle excision (three patients), breast mound revision (two patients), and mastopexy (one patient).

\section{Discussion}

The popularity and implementation of NSM continues to rise as its indications and outcomes continue to be defined. ${ }^{1-12}$ Autologous reconstruction in NSM is a safe and effective option that achieves an aesthetic, natural-appearing breast in a single stage. ${ }^{14,15}$ However, patients undergoing NSM may be more likely to have a low BMI with a paucity of adequate donor site tissue for reconstruction. ${ }^{14}$ Stacked microsurgical autologous flap reconstruction in both unilateral and bilateral breast reconstructions after total or skin-sparing mastectomy has been described. ${ }^{16-20}$

Stacked microsurgical breast reconstruction is an attractive option in patients undergoing NSM with inadequate single-flap donor tissue for an optimal reconstruction. Our experience found that patients undergoing NSM with stacked flap reconstruction had a low BMI, as expected. All patients were reconstructed with stacked DIEP flaps due to a lack of sufficient single-flap donor tissue to match the contralateral breast. While only DIEP flaps happened to be used and are generally the first choice in autologous flap reconstruction, thigh- or gluteal-based stacked flaps are also options. ${ }^{19}$ In our study, average total flap weight was greater than the average mastectomy specimen weight. However, the average estimated weight of individual flaps (half of the average total stacked flap weight) was significantly less than the average mastectomy specimen. In cases were the total flap weight is greater than necessary, the flap may be trimmed as needed. This is a superior situation than having insufficient tissue to match the contralateral side if a single flap only is used.
Stacked microsurgical flap reconstruction is especially advantageous in patients undergoing unilateral NSM. Stacked flaps will optimally match the contralateral breast in patients with inadequate donor tissue for single-flap techniques. Stacked autologous flaps also allow for a natural, ptotic appearance that is not achievable in implantbased breast reconstruction. This is evident in our review as all patients undergoing stacked flap reconstruction after NSM were in unilateral cases. There has recently been an increase in the number of patients undergoing contralateral prophylactic mastectomy for unilateral breast cancer despite no clear association with decreased recurrence or improved survival rates. ${ }^{21,22}$ This may be due to several factors including disease stage, socioeconomic factors, and influences from popular culture. ${ }^{21-24}$ Another consideration that may be leading to higher rates of bilateral mastectomies is the concern of difficulty matching a contralateral normal breast with either prosthetic or autologous reconstruction. Stacked autologous flaps in NSM allows for a symmetrical reconstruction to match the contralateral side without the need for a contralateral prophylactic mastectomy, which may increase patient morbidity. ${ }^{25}$ It should be noted, however, that in cases where bilateral NSM is indicated, four-flap techniques with bilateral stacked flap reconstructions, not discussed in this series, are possible and may be used.

In our series, there were no incidences of flap loss or other major complications, despite two patients having previous radiation therapy and all patients undergoing NSM for a therapeutic indication or having a history of breast cancer. Moreover, the majority of stacked flaps in our series were anastomosed in an anterograde/retrograde fashion to the IMA vessels with one flap anastomosed in a serial fashion. This demonstrates that the procedure is safe regardless of anastomotic technique. Lastly, all reconstructions were monitored with a skin paddle for each hemiflap of the stacked flap, while an implantable Doppler probe was used as an adjunct in one case. Thus, these cases in general do not require any adjunctive methods of flap monitoring, but rather simple skin paddle observation is sufficient.

It is also important to note that patients undergoing stacked flap reconstruction in NSM averaged 0.83 secondary procedures per patient. In our practice, each patient is generally offered a secondary procedure for skin paddle excision. Patients will also be offered fat grafting or other revisional procedures on an individualized basis. However, this is not mandatory, and stacked microsurgical breast reconstruction after NSM can be considered a single-stage procedure.

In conclusion, stacked autologous microsurgical breast flaps provide an optimal reconstruction after NSM and may be considered the reconstruction of choice in patients undergoing unilateral NSM with inadequate donor site tissue for single-flap reconstruction.

Funding

None. 


\section{References}

1 De La Cruz L, Moody AM, Tappy EE, Blankenship SA, Hecht EM. Overall survival, disease-free survival, local recurrence, and nipple-areolar recurrence in the setting of nipple-sparing mastectomy: a meta-analysis and systematic review. Ann Surg Oncol 2015; 22(10):3241-3249

2 Peled AW, Wang F, Foster RD, et al. Expanding the indications for total skin-sparing mastectomy: is it safe for patients with locally advanced disease? Ann Surg Oncol 2016;23(1):87-91

3 Seki T, Jinno H, Okabayashi K, et al. Comparison of oncological safety between nipple sparing mastectomy and total mastectomy using propensity score matching. Ann R Coll Surg Engl 2015;97(4):291-297

4 Frey JD, Alperovich M, Kim JC, et al. Oncologic outcomes after nipple-sparing mastectomy: a single-institution experience.J Surg Oncol 2016;113(1):8-11

5 Burdge EC, Yuen J, Hardee M, et al. Nipple skin-sparing mastectomy is feasible for advanced disease. Ann Surg Oncol 2013;20(10): 3294-3302

6 Coopey SB, Tang R, Lei L, et al. Increasing eligibility for nipplesparing mastectomy. Ann Surg Oncol 2013;20(10):3218-3222

7 Reish RG, Lin A, Phillips NA, et al. Breast reconstruction outcomes after nipple-sparing mastectomy and radiation therapy. Plast Reconstr Surg 2015;135(4):959-966

8 Dent BL, Small K, Swistel A, Talmor M. Nipple-areolar complex ischemia after nipple-sparing mastectomy with immediate implant-based reconstruction: risk factors and the success of conservative treatment. Aesthet Surg J 2014;34(4):560-570

9 Colwell AS, Tessler O, Lin AM, et al. Breast reconstruction following nipple-sparing mastectomy: predictors of complications, reconstruction outcomes, and 5-year trends. Plast Reconstr Surg 2014; 133(3):496-506

10 Carlson GW, Chu CK, Moyer HR, Duggal C, Losken A. Predictors of nipple ischemia after nipple sparing mastectomy. Breast J 2014; 20(1):69-73

11 Matsen CB, Mehrara B, Eaton A, et al. Skin flap necrosis after mastectomy with reconstruction: a prospective study. Ann Surg Oncol 2016;23(1):257-264

12 Alperovich M, Choi M, Frey JD, et al. Nipple-sparing mastectomy in patients with prior breast irradiation: are patients at higher risk for reconstructive complications? Plast Reconstr Surg 2014; 134(2):202e-206e

13 Lee KT, Mun GH. Comparison of one-stage vs two-stage prosthesis-based breast reconstruction: a systematic review and meta- analysis. Am J Surg 2015 (e-pub ahead of print). doi: 10.1016/j. amjsurg.2015.07.015

14 Raghavan S, Peled AW, Hansen SL, Esserman LJ, Sbitany H. Approaches to microvascular breast reconstruction after total skin-sparing mastectomy: a comparison of techniques. Ann Plast Surg 2015;74(Suppl 1):S46-S51

15 Tanna N, Broer PN, Weichman KE, et al. Microsurgical breast reconstruction for nipple-sparing mastectomy. Plast Reconstr Surg 2013;131(2):139e-147e

16 Stalder MW, Lam J, Allen RJ, Sadeghi A. Using the retrograde internal mammary system for stacked perforator flap breast reconstruction: 71 breast reconstructions in 53 consecutive patients. Plast Reconstr Surg 2016;137(2):265e-277e

17 Mayo JL, Allen RJ, Sadeghi A. Four-flap breast reconstruction: bilateral stacked DIEP and PAP flaps. Plast Reconstr Surg Glob Open 2015;3(5):e383

18 Murray A, Wasiak J, Rozen WM, Ferris S, Grinsell D. Stacked abdominal flap for unilateral breast reconstruction. J Reconstr Microsurg 2015;31(3):179-186

19 Blechman KM, Broer PN, Tanna N, Ireton JE, Ahn CY, Allen RJ. Stacked profunda artery perforator flaps for unilateral breast reconstruction: a case report. J Reconstr Microsurg 2013;29(9): 631-634

20 DellaCroce FJ, Sullivan SK, Trahan C. Stacked deep inferior epigastric perforator flap breast reconstruction: a review of 110 flaps in 55 cases over 3 years. Plast Reconstr Surg 2011;127(3):1093-1099

21 Freedman RA, Kouri EM, West DW, et al. Higher stage of disease is associated with bilateral mastectomy among patients with breast cancer: a population-based survey. Clin Breast Cancer 2016;16(2): 105-112

22 Hoskin TL, Hieken TJ, Degnim AC, Jakub JW, Jacobson SR, Boughey JC. Use of immediate breast reconstruction and choice for contralateral prophylactic mastectomy. Surgery 2016;159(4):1199-1209

23 Angelos P, Bedrosian I, Euhus DM, Herrmann VM, Katz SJ, Pusic A. Contralateral prophylactic mastectomy: challenging considerations for the surgeon. Ann Surg Oncol 2015;22(10):3208-3212

24 Grossman SG. The Angelina Jolie effect in Jewish law: prophylactic mastectomy and oophorectomy in BRCA carriers. Rambam Maimonides Med J 2015;6(4):e0037

25 Momoh AO, Cohen WA, Kidwell KM, et al. Breast reconstruction in patients with unilateral breast cancer who choose contralateral prophylactic mastectomy - an assessment of postoperative morbidity. Plast Reconstr Surg 2015;136(4, Suppl)116-117 